\title{
Cardiometabolic risk factors among HIV patients on antiretroviral therapy
}

James N Kiage ${ }^{1}$, Douglas C Heimburger ${ }^{1,4,5}$, Christopher K Nyirenda ${ }^{6}$, Melissa F Wellons², Shashwatee Bagchi ${ }^{7}$, Benjamin H Chi ${ }^{8,9}$, John R Koethe ${ }^{3,8}$, Donna K Arnett ${ }^{10}$ and Edmond K Kabagambe ${ }^{1,10^{*}}$

\begin{abstract}
Background: HIV and combination antiretroviral therapy (CART) may increase cardiovascular disease (CVD) risk. We assessed the early effects of CART on CVD risk markers in a population with presumed low CVD risk.

Methods: Adult patients ( $n=118$ ) in Lusaka, Zambia were recruited at the time of initiation of CART for HIV/AIDS. Cardiometabolic risk factors were measured before and 90 days after starting CART. Participants were grouped according to CART regimens: Zidovudine + Lamivudine + Nevirapine $(n=58) ;$ Stavudine + Lamivudine + Nevirapine $(n=43)$; and 'other' (Zidovudine + Lamivudine + Efavirenz, Stavudine + Lamivudine + Efavirenz, Tenofovir + Emtricitabine + Efavirenz or Tenofovir + Emtricitabine + Nevirapine, $n=17)$. ANOVA was used to test whether changes in cardiometabolic risk markers varied by CART regimen.

Results: From baseline to 90 days after initiation of CART, the prevalence of low levels of high-density lipoprotein cholesterol ( $<1.04 \mathrm{mmol} / \mathrm{L}$ for men and $<1.30 \mathrm{mmol} / \mathrm{L}$ for women) significantly decreased (78.8\% vs. 34.8\%, $P<0.001)$ while elevated total cholesterol $(T C \geq 5.18 \mathrm{mmol} / \mathrm{L}, 5.1 \%$ vs. $11.9 \%, P=0.03)$ and the homeostasis model assessment of insulin resistance $\geq 3.0(1.7 \%$ vs. $17.0 \%, P<0.001)$ significantly increased. The prevalence of TC:HDL-C ratio $\geq 5.0$ significantly decreased ( $44.9 \%$ vs. $6.8 \%, P<0.001)$. These changes in cardiometabolic risk markers were independent of the CART regimen.
\end{abstract}

Conclusion: Our results suggest that short-term CART is associated with a cardioprotective lipid profile in Zambia and a tendency towards insulin resistance regardless of the CART regimen.

Keywords: Lipids, CART, Cardiometabolic risk, Zambia

\section{Introduction}

HIV/AIDS patients have increased risk for adverse cardiovascular outcomes and diabetes [1-3]. Both the HIV infection and combination antiretroviral therapy (cART) are independently associated with increased cardiometabolic risk $[4,5]$.

Studies, mainly from developed countries, have shown that certain cART regimens, particularly combinations containing protease inhibitors, are associated with increased serum triglycerides (TG), low-density lipoprotein cholesterol (LDL-c) and total cholesterol (TC) as well as insulin resistance, while little or no effect is seen on high-

\footnotetext{
* Correspondence: edmond.kabagambe@vanderbilt.edu 'Department of Medicine, Division of Epidemiology, Vanderbilt University, Nashville, TN 37203, USA

${ }^{10}$ Department of Epidemiology, University of Alabama at Birmingham, Birmingham, AL 35294, USA

Full list of author information is available at the end of the article
}

density lipoprotein cholesterol (HDL-c) [6-8]. This constellation of dyslipidemia, especially elevation of TC:HDL-c ratio, and insulin resistance is thought to enhance the process of atherosclerosis, thus partly explaining the link between cART and adverse cardiometabolic outcomes [9-11]. Although protease inhibitor sparing combinations have also been associated with similar lipid changes, they result in substantial HDL-c elevation and relatively lower elevations of TG and LDL-c [6]. This lipid profile, especially the elevation of HDL-c, is thought to be beneficial to cardiovascular health $[6,11,12]$.

However, few studies have explored the association between CART and cardiovascular health within resourceconstrained settings where the majority of HIV/AIDS cases reside and where the prevalence of traditional cardiovascular risk factors, such as excess adiposity, a high fat diet, and smoking, may be lower [13-15]. Findings

\section{Biomed Central}


from developed countries may not hold in resource-poor settings due to factors that could potentially modify cardiovascular risk e.g., age of the population, differences in HIV subtypes, diet, lifestyle as well as genetics [14]. The ongoing expansion of the cART programs within resource-limited settings highlights the need to quantify cardiometabolic risk associated with different antiretroviral combinations in these settings $[15,16]$.

Using serum lipids and markers of insulin resistance as cardiometabolic risk markers, we investigated changes in cardiometabolic risk following cART among treatmentnaive HIV positive patients initiating therapy in Zambia. We also tested whether the changes in cardiometabolic risk markers varied by cART regimen.

\section{Methods}

\section{Ethics statement}

The study was approved by the Institutional Review Board of the University of Alabama at Birmingham (UAB) and the Research Ethics Committee of the University of Zambia. All participants gave written informed consent.

\section{Study design and population}

The current analysis is based on data from the Diet, Genetic Polymorphisms in Lipid-Metabolizing Enzyme genes, and Antiretroviral Therapy-Related Dyslipidemia (DGPLEAD) study which was carried out in Chawama Clinic, Lusaka, Zambia. The study has been described elsewhere [17]. In brief, 210 cART-naïve HIV/AIDS patients were recruited between January and December 2007. Men and women aged 16.5-60 years who were eligible to begin cART according to the Zambia HIV national guidelines and had BMI $\geq 16 \mathrm{~kg} / \mathrm{m}^{2}$ and $\mathrm{CD} 4+$ lymphocyte count $\geq 50$ cells $/ \mu \mathrm{L}$ were invited into the study. All participants who gave consent were enrolled. The aforementioned BMI and CD4+ criteria were used because another study in the same clinic simultaneously recruited participants with $\mathrm{BMI}$ and $\mathrm{CD} 4+$ levels below these thresholds [18]. cART was prescribed according to the Zambian national guidelines at the time. Regimens comprised 2 nucleoside reverse transcriptase inhibitors (NRTI), for example zidovudine [AZT] and lamivudine [3TC] or stavudine [D4T] and lamivudine [3TC], and a non-nucleoside reverse transcriptase inhibitor, for example efavirenz $[\mathrm{EFV}]$ or nevirapine [NVP]. Tenofovir [TDF] and emtricitabine [FTC] were introduced into the first-line NRTI backbone in July 2007, while the study was underway [19]. No protease inhibitors were included in the regimens.

\section{Data collection}

At the initial visit, data on smoking, physical activity and alcohol intake were collected using standardized questionnaires. In addition, dietary intake was assessed using 24-hour dietary recalls; the Nutrition Data System for Research software was used to determine dietary nutrient content. Zambian foods not in the database were substituted with similar foods in the database using a recommended guideline [17]. Also added into the database were recipes for common foods which were collated through focus group meetings.

Anthropometric measurements including weight, height, waist circumference, hip circumference and mid-upper arm circumference were recorded as an average of two measurements made by a trained staff member. A blood specimen was taken from each participant after an 8-hour fast to determine lipid and metabolic profiles. Participants were followed, and their lipid and metabolic profiles and vital status were reassessed at 90 days following cART initiation.

\section{Laboratory tests}

Lipids and glucose were assayed using the Roche Cobas Integra 400+ auto analyzer (Roche Diagnostics, Indianapolis, IN, USA). An enzymatic colorimetric assay was used to measure TG, LDL-c and TC concentrations while a homogeneous enzymatic colorimetric assay was used to measure HDL-c. In addition, the hexokinase enzyme method was used to measure glucose concentration while insulin was assayed using chemiluminescence on the Roche Elecsys 2010 autoanalyzer. Serum albumin, creatinine and high-sensitivity $\mathrm{C}$-reactive protein (CRP) were measured on a Roche Modular P analyzer using bromocresol purple assay for albumin and immunoturbidimetric assay for CRP (Roche Diagnostics, Indianapolis, IN, USA).

\section{Statistical analysis}

Only participants with both baseline and 90-day lipid and other metabolic measurements were included in the current analysis. cART regimens were grouped into 3 categories as follows: $\mathrm{AZT}+3 \mathrm{TC}+\mathrm{NVP}, \mathrm{D} 4 \mathrm{~T}+3 \mathrm{TC}+\mathrm{NVP}$ and 'other' (AZT+3TC+EFV, D4T+3TC+EFV, TDF+FTC+EFV or $\mathrm{TDF}+\mathrm{FTC}+\mathrm{NVP})$. We compared baseline characteristics of participants by cART regimen using one-way ANOVA and Kruskal-Wallis tests for continuous variables and chi-square tests for categorical variables. We then tested lipid, insulin and glucose changes from baseline to 90 days using paired t-tests and Wilcoxon signed-rank tests. We stratified the data by the antiretroviral combinations and again tested whether changes were significant using Wilcoxon signed-rank tests. We used ANOVA models with robust variance estimators to determine whether the magnitude of changes in cardiometabolic markers varied by cART regimen; change from baseline to 90-day was the dependent variable and cART regimen and sex were the independent variables. Sex was included in 
these models because of the significant differences in sex by cART regimen (Table 1 ).

We used the US National Cholesterol Education Program Adult Treatment Panel III guidelines [10] to define abnormal lipid values as follows: TG $\geq 1.70 \mathrm{mmol} / \mathrm{L}(150 \mathrm{mg} / \mathrm{dL})$, LDL-c $\geq 3.37 \mathrm{mmol} / \mathrm{L}(130 \mathrm{mg} / \mathrm{dL}), \quad \mathrm{TC} \geq 5.18 \mathrm{mmol} / \mathrm{L}$ (200 mg/dL), and HDL-c <1.04 mmol/L (40 mg/dL) in men and $<1.30 \mathrm{mmol} / \mathrm{L}(50 \mathrm{mg} / \mathrm{dL})$ in women. We also defined TC:HDL-c ratio $\geq 5.0$ and glucose $\geq 5.55 \mathrm{mmol} / \mathrm{L}$ $(100 \mathrm{mg} / \mathrm{dL})$ as abnormal [13,20]. Participants with a homeostasis model assessment of insulin resistance (HOMA-IR) index $\geq 3.0$ were considered to be insulin resistant $[21,22]$. HOMA-IR was calculated using the following formula: fasting serum insulin $(\mu \mathrm{U} / \mathrm{mL}) \times$ fasting plasma glucose $(\mathrm{mmol} / \mathrm{L}) / 22.5$ [23]. We used McNemar's test to compare the prevalence of the abnormal values between baseline and 90 days. We repeated the analysis for HDL-c after redefining low HDL-c as $<1.04 \mathrm{mmol} / \mathrm{L}$ $(<40 \mathrm{mg} / \mathrm{dL})$ for both men and women to enable comparison with previous studies.

To determine the potential for selection bias, we compared baseline characteristics of participants who were included to those who were excluded from the current analysis. All analyses were done using SAS version 9.2 (SAS Institute Inc., Cary, NC, USA); differences were considered significant at $P \leq 0.05$.

\section{Results}

Of the 210 participants recruited into the DGPLEAD study, 134 had both baseline and 90-day information. We excluded 16 more participants for missing data on TC, HDL-c, LDL-c and medications, leaving 118 participants for the current analysis. Their summary statistics are shown in Table 1.

\section{Baseline characteristics}

The mean age \pm SD of the study population was $35.0 \pm$ 7.9 years; $55.5 \%$ were women. The majority of the participants $(85.6 \%)$ were either on $\mathrm{AZT}+3 \mathrm{TC}+\mathrm{NVP}$ or $\mathrm{D} 4 \mathrm{~T}$ $+3 \mathrm{TC}+\mathrm{NVP}$. Participants in various antiretroviral combination groups were similar $(P>0.05)$ with regard to age, body mass index (BMI; weight $(\mathrm{kg}) /$ height $\left.[\mathrm{m}]^{2}\right)$, waist circumference, hip circumference, mid-upper arm circumference, smoking, alcohol drinking, nutrient intake and lipid profiles at baseline. The majority of participants on AZT $+3 \mathrm{TC}$ $+\mathrm{NVP}$ were men while women were the majority in the $\mathrm{D} 4 \mathrm{~T}+3 \mathrm{TC}+\mathrm{NVP}$ and 'other' cART regimens. Participants on D4T+3TC+NVP, had a lower mean weight $(P=0.01)$ and height $(P<0.001)$, had a higher median CRP $(P=0.01)$ and a higher proportion of high CRP $(\geq 3.0 \mathrm{mg} / \mathrm{dL} ; P=0.05)$ compared to the participants on AZT+3TC+NVP or 'other' cART regimens. In addition, participants on $\mathrm{D} 4 \mathrm{~T}+3 \mathrm{TC}$ + NVP had a lower mean serum albumin $(P<0.001)$ and a higher proportion of low serum albumin $(<3.5 \mathrm{~g} / \mathrm{dL}$; $P<0.001)$.

\section{Changes from baseline to 90 days}

Table 2 shows lipid and other metabolic changes from baseline to 90 days. Total cholesterol, LDL-c and HDL-C concentrations significantly increased $(P<0.001, P=0.02$ and $P<0.001$, respectively); the increase in HDL-c was proportionately greater than that of TC, yielding a significant decrease in the TC:HDL-C ratio $(P<0.001)$. Insulin and HOMA-IR doubled $(P<0.001$ in both cases), while glucose and BMI increased significantly but less substantially ( $P=0.05$ and $P<0.001$, respectively). There was no significant change in TG concentrations $(P=0.36)$.

Analyses stratified by cART regimen (Table 3) showed significant increases $(P<0.05)$ in HDL-c and decreases in TC:HDL-c ratio from baseline to 90 days in all cART regimens. In addition, there were increases in TC, insulin, HOMA-IR and BMI across all 3 cART regimens, though this increase was statistically significant $(P<0.05)$ only in the AZT $+3 \mathrm{TC}+\mathrm{NVP}$ and D4T+3TC+NVP cART groups and not in the 'other' group $(P>0.05)$. Furthermore, only the group on $\mathrm{D} 4 \mathrm{~T}+3 \mathrm{TC}+\mathrm{NVP}$ had a significant increase in LDL-C $(P=0.02)$, while none of the groups exhibited a significant change $(P>0.05)$ in TG.

Except for TC $(P=0.04)$, none of the changes in cardiometabolic risk markers varied significantly by treatment group in analyses adjusted for sex (Table 3). In models further adjusted for age and BMI, the $P$-values for the treatment regimen remained essentially unchanged.

\section{Prevalence of lipid and metabolic abnormalities at baseline and 90 days}

As shown in Figure 1, the prevalence of TC $\geq 5.18 \mathrm{mmol} / \mathrm{L}$ significantly increased $(5.1 \%$ vs. $11.9 \%, P=0.02)$ while the prevalence of low HDL-c $(<1.04 \mathrm{mmol} / \mathrm{L}(<40 \mathrm{mg} / \mathrm{dL})$ in men and $<1.30 \mathrm{mmol} / \mathrm{L}(<50 \mathrm{mg} / \mathrm{dL})$ in women $)$, TC: HDL-c $\geq 5.0$ and BMI $<18.5 \mathrm{~kg} / \mathrm{m}^{2}$ significantly decreased $(P<0.05)$ from baseline to 90 days. In addition, the prevalence of HOMA-IR $\geq 3.0$ significantly increased from baseline to 90 days $(P<0.001)$.

Analysis of HDL-c after redefining low HDL-c as $<1.04 \mathrm{mmol} / \mathrm{L}$ for both men and women still showed a significant decrease from baseline to 90 days (baseline: $72.9 \%$ vs. 90 -day: $21.2 \%, P<0.001$, respectively). Although there were nominal elevations in the prevalence of LDL-c $\geq 3.37 \mathrm{mmol} / \mathrm{L}(\geq 130 \mathrm{mg} / \mathrm{dL})$ and glucose $>5.55 \mathrm{mmol} / \mathrm{L}$ (>100 $\mathrm{mg} / \mathrm{dL})$, the changes were not statistically significant $(P=0.48$ and $P=0.17$, respectively). There was no change in the prevalence of triglycerides $\geq 1.70 \mathrm{mmol} / \mathrm{L}$ ( $\geq 150 \mathrm{mg} / \mathrm{dL}, P=0.83)$. 
Table 1 Baseline characteristics of the DGPLEAD study overall and by combination antiretroviral therapy

\begin{tabular}{|c|c|c|c|c|c|}
\hline \multirow[b]{2}{*}{ Variable } & \multirow[b]{2}{*}{ Overall $(n=118)$} & \multicolumn{3}{|c|}{ Combination antiretroviral therapy } & \multirow[b]{2}{*}{$P *$} \\
\hline & & $\overline{A Z T+3 T C+N V P(n=58)}$ & $D 4 T+3 T C+N V P(n=43)$ & Other $\neq(n=17)$ & \\
\hline Age, yearst & $35.0 \pm 7.9$ & $36.7 \pm 7.5$ & $33.3 \pm 7.3$ & $33.5 \pm 9.7$ & 0.07 \\
\hline Gender, \% female & 55.9 & 41.4 & 72.1 & 64.7 & 0.01 \\
\hline $\mathrm{BMI}, \mathrm{kg} / \mathrm{m}^{2}$ & $20.2 \pm 2.7$ & $20.2 \pm 2.7$ & $20.0 \pm 2.4$ & $20.3 \pm 3.5$ & 0.86 \\
\hline \multicolumn{6}{|l|}{$\mathrm{BMI}, \%$} \\
\hline$<18.5 \mathrm{~kg} / \mathrm{m}^{2}$ & 29.7 & 27.6 & 27.9 & 41.2 & 0.63 \\
\hline $18.5-24.9 \mathrm{~kg} / \mathrm{m}^{2}$ & 63.6 & 67.2 & 65.1 & 47.1 & \\
\hline$\geq 25.0 \mathrm{~kg} / \mathrm{m}^{2}$ & 6.8 & 5.2 & 7.0 & 11.8 & \\
\hline Weight, kg & $54.9 \pm 8.7$ & $57.2 \pm 9.0$ & $51.9 \pm 7.1$ & $54.4 \pm 9.7$ & 0.01 \\
\hline Height, m & $1.65 \pm 0.08$ & $1.68 \pm 0.07$ & $1.61 \pm 0.07$ & $1.64 \pm 0.07$ & $<0.001$ \\
\hline Waist circumference, $\mathrm{cm}$ & $72.9 \pm 6.7$ & $73.8 \pm 7.2$ & $72.7 \pm 6.0$ & $70.2 \pm 6.3$ & 0.16 \\
\hline Hip circumference, $\mathrm{cm}$ & $89.1 \pm 7.0$ & $90.1 \pm 7.4$ & $88.1 \pm 6.2$ & $88.2 \pm 7.7$ & 0.32 \\
\hline MUAC, cm & $24.9 \pm 2.6$ & $25.4 \pm 2.7$ & $24.2 \pm 2.1$ & $24.9 \pm 2.9$ & 0.06 \\
\hline Current smoker, \% † & 4.4 & 7.1 & 2.3 & 0.0 & 0.33 \\
\hline Current drinker, $\% †$ & 9.6 & 14.3 & 4.7 & 6.3 & 0.24 \\
\hline Total energy intake, kcal/day & $1750 \pm 651$ & $1840 \pm 641$ & $1620 \pm 604$ & $1770 \pm 773$ & 0.25 \\
\hline Total fat, \% energy/day & $31.7 \pm 10.8$ & $29.3 \pm 9.5$ & $34.0 \pm 11.2$ & $34.5 \pm 12.4$ & 0.05 \\
\hline MUFA, \% energy/day & $9.1 \pm 3.5$ & $8.3 \pm 3.0$ & $9.8 \pm 4.2$ & $9.8 \pm 3.1$ & 0.07 \\
\hline PUFA, \% energy/day & $14.1 \pm 5.9$ & $12.8 \pm 5.0$ & $15.2 \pm 5.9$ & $15.4 \pm 7.9$ & 0.07 \\
\hline Saturated fat, \% energy/day & $6.3 \pm 2.5$ & $6.0 \pm 2.5$ & $6.6 \pm 2.7$ & $6.8 \pm 2.4$ & 0.37 \\
\hline Carbohydrates, \% energy/day & $56.1 \pm 12.4$ & $58.0 \pm 11.5$ & $54.2 \pm 12.8$ & $54.5 \pm 14.3$ & 0.27 \\
\hline Proteins, \% energy/day & $12.9 \pm 3.9$ & $13.4 \pm 4.2$ & $12.6 \pm 4.0$ & $12.0 \pm 2.2$ & 0.34 \\
\hline CD4 count, cells/ $\mu \mathrm{L}$ & $136 \pm 50$ & $137 \pm 45$ & $133 \pm 51$ & $138 \pm 65$ & 0.87 \\
\hline$C R P, m g / L \dagger$ & $9.48[2.04,25.94]$ & $5.62[1.31,17.36]$ & $16.62[5.51,44.31]$ & $4.05[1.64,25.62]$ & 0.01 \\
\hline $\mathrm{CRP} \geq 3.0 \mathrm{mg} / \mathrm{L}, \%+$ & 70.4 & 63.5 & 84.6 & 58.8 & 0.05 \\
\hline Albumin, $\mathrm{g} / \mathrm{dL} \dagger$ & $3.11 \pm 0.71$ & $3.44 \pm 0.59$ & $2.67 \pm 0.64$ & $3.14 \pm 0.67$ & $<0.001$ \\
\hline Albumin $<3.5 \mathrm{~g} / \mathrm{dL}, \%+$ & 65.7 & 48.1 & 89.7 & 64.7 & $<0.001$ \\
\hline Creatinine $\geq 2.0 \mathrm{mg} / \mathrm{dL}, \% \dagger$ & 0.93 & 0.0 & 2.6 & 0.0 & 0.41 \\
\hline Fasting insulin, $\mu \mathrm{U} / \mathrm{mL}+$ & $3.00[1.90,5.40]$ & $3.00[2.00,5.00]$ & $3.00[1.50,5.00]$ & $2.60[1.20,5.90]$ & 0.80 \\
\hline Fasting glucose, $\mathrm{mmol} / \mathrm{L} \dagger$ & $3.80[3.40,4.10]$ & $3.90[3.60,4.30]$ & $3.70[3.40,4.10]$ & $3.60[3.00,3.90]$ & 0.02 \\
\hline HOMA-IR & $0.51[0.30,0.98]$ & $0.53[0.33,0.93]$ & $0.50[0.28,1.00]$ & $0.45[0.16,0.98]$ & 0.63 \\
\hline Total cholesterol, mmol/L & $3.56 \pm 0.83$ & $3.68 \pm 0.75$ & $3.42 \pm 0.92$ & $3.52 \pm 0.86$ & 0.27 \\
\hline Triglycerides, mmol/L & $1.02[0.85,1.37]$ & $1.01[0.86,1.33]$ & $1.16[0.88,1.60]$ & $0.95[0.77,1.05]$ & 0.15 \\
\hline LDL-cholesterol, mmol/L & $2.12 \pm 0.75$ & $2.26 \pm 0.62$ & $1.93 \pm 0.89$ & $2.10 \pm 0.68$ & 0.10 \\
\hline HDL-cholesterol, mmol/L & $0.72[0.52,1.09]$ & $0.80[0.61,1.15]$ & $0.65[0.34,0.92]$ & $0.76[0.57,1.03]$ & 0.08 \\
\hline TC:HDL-c ratio & $4.77[3.51,6.30]$ & $4.54[3.44,5.84]$ & $5.32[3.97,8.93]$ & $4.34[3.33,5.82]$ & 0.15 \\
\hline
\end{tabular}

DGPLEAD, Diet, Genetic Polymorphisms in Lipid-Metabolizing Enzyme genes, and Antiretroviral Therapy-Related Dyslipidemia; BMI, Body Mass Index; MUAC, Mid Upper Arm Circumference; MUFA, Monounsaturated Fatty Acids; PUFA, Polyunsaturated Fatty Acids; CRP, C-reactive Protein; LDL, Low Density Lipoprotein; HDL, High Density Lipoprotein; TC, Total Cholesterol; HOMA-IR, Homeostatic model assessment of insulin resistance.

Values are reported as mean \pm standard deviation, median $\left[25^{\text {th }}\right.$ percentile, $75^{\text {th }}$ percentile] or percent

$\neq \mathrm{AZT}+3 \mathrm{TC}+\mathrm{EFV}, \mathrm{D} 4 \mathrm{~T}+3 \mathrm{TC}+\mathrm{EFV}, \mathrm{TDF}+\mathrm{FTC}+\mathrm{EFV}$, or TDF+FTC+NVP.

* P-values for the comparison between CART regimens were obtained through one-way ANOVA or Kruskal-Wallis tests for continuous variables and from Chi-square tests for categorical variables.

+ Variables with missing values -1 for glucose, 2 for age, 3 for both smoking and alcohol status, 10 for CRP, albumin and creatinine and 20 for insulin. 
Table 2 Lipid and metabolic changes from baseline to 90 days of combination antiretroviral therapy

\begin{tabular}{lccc}
\hline Variable & Baseline $(\mathbf{n}=\mathbf{1 1 8})$ & End $(\mathbf{n}=\mathbf{1 1 8})$ & $\boldsymbol{P}^{*}$ for change \\
\hline HDL-cholesterol, mmol/L & $0.72[0.52,1.09]$ & $1.34[1.09,1.70]$ & $<0.001$ \\
LDL-cholesterol, mmol/L & $2.12 \pm 0.75$ & $2.28 \pm 0.59$ & 0.02 \\
Total cholesterol, mmol/L & $3.56 \pm 0.83$ & $4.09 \pm 0.86$ & $<0.001$ \\
Triglycerides, mmol/L & $1.02[0.85,1.37]$ & $1.03[0.79,1.37]$ & 0.36 \\
TC:HDL-c ratio & $4.77[3.51,6.30]$ & $2.93[2.38,3.69]$ & $<0.001$ \\
Insulin, $\mu \mathrm{UU} / \mathrm{mL}$ & $3.00[1.90,5.40]$ & $6.40[3.40,12.50]$ & $<0.001$ \\
Glucose, $\mathrm{mmol} / \mathrm{L}$ & $3.80[3.40,4.10]$ & $4.00[3.40,4.50]$ & 0.048 \\
HOMA-IR & $0.51[0.30,0.98]$ & $1.12[0.61,2.21]$ & $<0.001$ \\
BMl, $\mathrm{kg} / \mathrm{m}^{2}$ & $20.15 \pm 2.70$ & $20.89 \pm 2.92$ & $<0.001$ \\
Weight, $\mathrm{kg}$ & $54.9 \pm 8.7$ & $56.8 \pm 9.0$ & $<0.001$ \\
\hline
\end{tabular}

Values are reported as mean \pm standard deviation or median $\left[25^{\text {th }}\right.$ percentile, $75^{\text {th }}$ percentile].

* $P$-values obtained from paired t-tests or Wilcoxon Signed rank tests.

\section{Additional analyses}

A comparison between participants whose data were included vs. excluded from the current analysis showed that the two groups were similar $(P>0.05)$ with regard to sex, BMI, waist circumference, hip circumference, mid-upper arm circumference, smoking, CD4 cell count, CRP, serum albumin, TG, HDL-c, TC:HDL-c ratio, and intakes of alcohol, total energy and \% energy from total fat, monounsaturated fat, polyunsaturated fat, saturated fat, proteins and carbohydrates. However, excluded participants had a significantly lower mean age compared to those included in the study $(32.7 \pm 6.4$ SD years vs. $35.0 \pm 7.9$ years in those included, $P=0.03)$. In addition, excluded participants had lower mean LDL-c $(1.82 \pm 0.77 \mathrm{SD} \mathrm{mmol} / \mathrm{L}$ vs. $2.12 \pm 0.75$ $\mathrm{mmol} / \mathrm{L}$ in those included, $P=0.01)$ and TC $(3.30 \pm 1.03$ $\mathrm{mmol} / \mathrm{L}$ vs. $3.56 \pm 0.83 \mathrm{mmol} / \mathrm{L}$ in those included, $P=0.04$ ).

\section{Discussion}

This study showed that in the first 90 days, cART regimens prescribed to HIV/AIDS patients in Zambia in 2007 were associated with moderate increases in LDL-c and TC and substantial increases in HDL-c, leading to a substantial reduction in the TC:HDL-c ratio. Serum insulin, glucose and the HOMA-IR index also increased, suggesting a tendency towards insulin resistance. These changes were independent of the cART regimen.

The observed short-term lipid and metabolic changes are not likely to be associated with an increase in the risk of adverse cardiovascular outcomes since they mostly remained below established cut-points for increased cardiovascular disease risk in developed countries. The actual lipid cut-points associated with cardiovascular risk in developing countries are unknown. The significant increase in HDL-c and the consequent decrease in the TC:HDL-c ratio may suggest a cardioprotective effect of antiretroviral therapy $[7,10,24,25]$. This finding is consistent with results from the $2 \mathrm{NN}$ trial in which NVP compared to EFV conferred a better lipid profile [26]. The overall improved lipid profile in our study could in part be due to the fact that $95 \%$ of the patients were on NVP-based therapy. The observed improved lipid profile is of great interest given previous reports have suggested increased cardiovascular risk by HIV itself as well as by some cART [1,3]. The marginally significant difference in TC change among the three cART regimens was driven by the change in the 'other' group which, although smaller, was similar in direction to the change in the two main cART regimens. In addition to comprising many cART regimens (including AZT and $\mathrm{D} 4 \mathrm{~T})$, the 'other' group has a small sample size $(\mathrm{n}=17)$, making the observed value more likely due to chance.

In agreement with our study findings, a two-year prospective study conducted in Uganda by Buchacz et al. [13] among 374 cART-naive patients showed that TC and HDL-c were significantly higher $(P<0.05)$ at one and two years following initiation of therapy compared to the baseline values. Buchacz et al. also showed that the TC:HDL-c ratio was significantly lower at one and two years compared to the baseline value. Additionally, a cross-sectional study among HIV/AIDS patients initiating cART in Tanzania reported lipid values that are comparable to those observed in the current study [14]. Furthermore, concordant with our findings, crosssectional studies in Kenya [27] and India [28] comparing cART-naïve and treated groups showed that patients on cART had significantly higher $(P<0.05)$ TC, LDL-c and HDL-c.

Moreover, in agreement with our findings, a study conducted in Cameroon by Yone et al. [29] compared cART-naïve HIV/AIDS patients with patients who had been on first-line cART for 12 months and reported that patients on cART had higher TC and LDL-c. Contrary to our findings, Yone et al. reported that patients on 
Table 3 Comparison of metabolic changes by period and combination antiretroviral therapy regimen in the DGPLEAD study

\begin{tabular}{|c|c|c|c|c|c|c|c|c|c|c|}
\hline \multirow[b]{2}{*}{ Variable } & \multicolumn{3}{|c|}{$A Z T+3 T C+N V P(n=58)$} & \multicolumn{3}{|c|}{ D4T+3TC+NVP $(n=43)$} & \multicolumn{3}{|c|}{ Other $(n=17)$} & \multirow{2}{*}{$\underset{P * *}{\text { Globa }}$} \\
\hline & Baseline & End & $P^{*}$ & Baseline & End & $P^{*}$ & Baseline & End & $P^{*}$ & \\
\hline $\mathrm{HDL}-\mathrm{c}, \mathrm{mmol} / \mathrm{L}$ & $0.80[0.61,1.15]$ & $1.42[1.17,1.73]$ & $<0.001$ & $0.65[0.34,0.92]$ & $1.27[1.02,1.70]$ & $<0.001$ & $0.76[0.57,1.03]$ & $1.22[0.96,1.47]$ & 0.003 & 0.22 \\
\hline LDL-C, mmol/L & $2.24[1.76,2.52]$ & $2.25[2.00,2.75]$ & 0.51 & $2.01[1.44,2.42]$ & $2.27[1.81,2.61]$ & 0.007 & $2.06[1.71,2.58]$ & $2.14[1.84,2.18]$ & 0.41 & 0.13 \\
\hline $\mathrm{TC}, \mathrm{mmol} / \mathrm{L}$ & $3.59[3.23,3.99]$ & $4.00[3.50,4.68]$ & $<0.001$ & $3.46[2.85,4.08]$ & $4.13[3.59,4.58]$ & $<0.001$ & $3.40[2.86,3.87]$ & $3.50[3.40,3.73]$ & 0.77 & 0.04 \\
\hline TC:HDL-c ratio & $4.54[3.44,5.84]$ & $2.78[2.34,3.49]$ & $<0.001$ & $5.32[3.97,8.93]$ & $3.08[2.85,3.94]$ & $<0.001$ & $4.34[3.33,5.82]$ & $2.73[2.31,3.00]$ & 0.001 & 0.36 \\
\hline $\mathrm{TG}, \mathrm{mmol} / \mathrm{L}$ & $1.01[0.86,1.33]$ & $1.06[0.70,1.41]$ & 0.93 & $1.16[1.88,1.60]$ & $1.05[0.85,1.44]$ & 0.41 & $0.95[0.77,1.05]$ & $0.91[0.68,1.14]$ & 0.17 & 0.33 \\
\hline Insulin, $\mu \mathrm{U} / \mathrm{mL}$ & $3.00[2.00,5.00]$ & $6.70[4.00,12.50]$ & $<0.001$ & $3.00[1.50,5.00]$ & $7.65[3.00,13.45]$ & $<0.001$ & $2.60[1.20,5.90]$ & $4.65[3.15,9.70]$ & 0.07 & 0.18 \\
\hline Glucose, mmol/L & $3.90[3.60,4.30]$ & $4.20[3.60,4.60]$ & 0.37 & $3.70[3.40,4.10]$ & $3.80[3.20,4.60]$ & 0.23 & $3.60[3.00,3.90]$ & $3.70[3.50,4.20]$ & 0.17 & 0.79 \\
\hline HOMA-IR & $0.53[0.33,0.93]$ & $1.12[0.62,2.41]$ & $<0.001$ & $0.50[0.28,1.00]$ & $1.39[0.49,2.49]$ & $<0.001$ & $0.45[0.16,0.98]$ & $0.72[0.49,1.53]$ & 0.08 & 0.07 \\
\hline $\mathrm{BMI}, \mathrm{kg} / \mathrm{m}^{2}$ & $20.1[18.2,21.5]$ & $20.3[19.1,22.2]$ & 0.001 & $19.6[18.4,21.1]$ & $20.6[19.2,22.4]$ & $<0.001$ & $19.4[17.6,22.4]$ & $20.1[18.6,22.3]$ & 0.49 & 0.26 \\
\hline Weight, kg & $55.3[51.0,62.0]$ & $58.0[53.5,64.0]$ & 0.001 & $52.0[46.0,55.0]$ & $56.0[47.0,59.0]$ & $<0.001$ & $53.0[49.0,60.5]$ & $55.0[50.0,57.0]$ & 0.49 & 0.30 \\
\hline
\end{tabular}

Values are reported as median $\left[25^{\text {th }}\right.$ percentile, $75^{\text {th }}$ percentile].

* $P$-values obtained through Wilcoxon signed rank tests.

** P-values are from ANOVA with robust variance estimators comparing changes from baseline to 90 days after initiating CART and are adjusted for sex.

DGPLEAD, Diet, Genetic Polymorphisms in Lipid-Metabolizing Enzyme genes, and Antiretroviral Therapy-Related Dyslipidemia. 


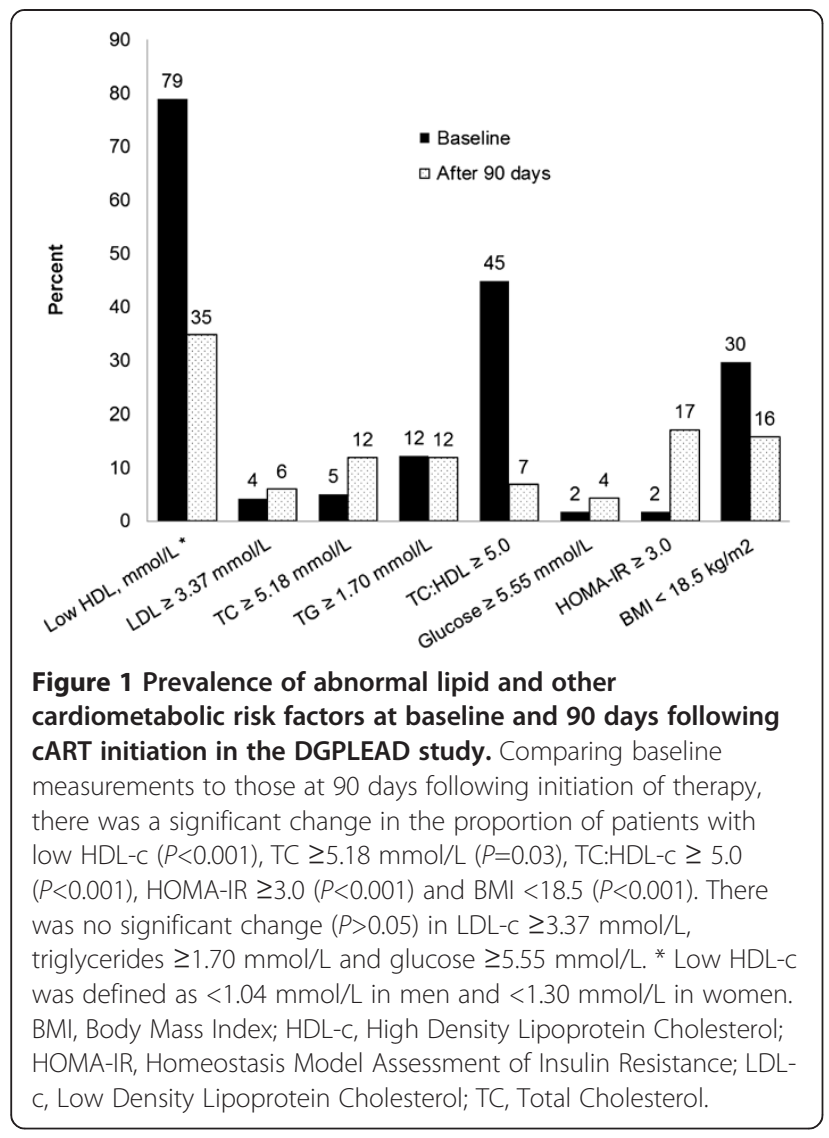

cART had similar HDL-c concentration with cARTnaïve patients and also a higher TC:HDL-c ratio. Due to the cross-sectional study design, it is impossible to know whether the HDL-c concentration and the TC:HDL-c ratio among patients on CART improved or worsened following initiation of therapy. In addition, this study [29] only included patients who did not switch medications, which may have introduced selection bias.

Our study findings also indicate a significant increase $(P<0.05)$ in serum insulin concentration, glucose and HOMA-IR index in the AZT $+3 \mathrm{TC}+\mathrm{NVP}$ and D4T $+3 \mathrm{TC}+\mathrm{NVP}$ cART regimen groups, suggesting that cART may increase insulin resistance [22,30]. Similar observations have been reported by Pujari et al. in India [28]. Moreover, studies from developed countries using the euglycemic clamp protocol to assess insulin resistance have shown that NRTIs, particularly AZT or $\mathrm{D} 4 \mathrm{~T}$, are associated with increased insulin resistance $[31,32]$. Our results should be corroborated using more accurate measures of insulin resistance; if confirmed, it may be a concern because insulin resistance is an established risk factor for diabetes mellitus and cardiovascular disease $[33,34]$.

About $44 \%$ of the recruited patients were excluded, mainly due to early termination of the study [17], raising a concern for selection bias. A comparison between patients whose data were included to those whose data were excluded indicates that the excluded patients were younger, had lower LDL-c and lower TC but similar in most other characteristics at baseline. Although age is a known modulator of cardiovascular risk [10], little is known about the effect of age on the risk for adverse cardiovascular outcomes in young people, and we speculate that a 2.3 years age difference between those included and those excluded in a young population may not result in a clinically meaningful risk difference. In addition, despite the slight differences in LDL-c and TC, the two groups had similar HDL-c and TC: HDL-c ratios, suggesting that they did not differ with regard to risk for adverse cardiovascular outcomes [10]. It is also noteworthy that despite the lipid differences, the mean TC level for the included and excluded patients was still much lower than the $200 \mathrm{mg} / \mathrm{dL}$ cutpoint. Moreover, the two groups were similar in composition by sex, anthropometric measures, nutritional status, and serum inflammatory marker levels, all of which are strong modulators of cardiometabolic risk [10,35-40].

Unlike studies conducted in developed countries, none of the participants in our study reported use of any lipid-lowering drugs, eliminating confounding from such medications.

We acknowledge a number of limitations in our study. First, the study lacked a control group which makes it difficult to differentiate the effect of regression to the mean from the effect of cART. Second, we were not able to measure CRP concentrations at the 90-day follow-up. CRP is a strong correlate of cardiometabolic risk [3]. Third, we lacked baseline viral load values because they were not part of standard of care in Zambia at the time of the study and could not be measured for the current analysis due to financial constraints. Viral load measurements are important markers of disease progression in HIV infected patients and could influence response to antiretroviral therapy. However, the 3 cART regimen categories had similar CD4 cell counts $(P=0.87)$ indicating no obvious differences in disease progression between the 3 treatment categories. Fourth, our study had a short follow-up period of 90 days, a period during which underweight or emaciated patients may still be resetting their metabolic profiles following treatment. However, the few studies in resource poor settings that have followed patients for a longer period (up to 24 months) have reported similar associations [13].

Nevertheless, larger and longer studies are warranted to examine the effects of different cART regimens on cardiometabolic risk and outcomes in sub-Saharan African populations. 


\section{Conclusions}

Our results suggest that first-line cART regimens in Zambia that did not include protease inhibitors are associated with cardioprotective lipid profiles characterized by a substantial increase in HDL-c and a decrease in the TC:HDL-c ratio. Our findings of increased insulin and HOMA-IR suggest a tendency towards insulin resistance. These results appear to be independent of the cART regimen used.

\section{Abbreviations}

3TC: Lamivudine; AIDS: Acquired immune deficiency syndrome; AZT: Zidovudine; BMI: Body mass index; CART: Combination antiretroviral therapy; CRP: C-reactive protein; D4T: Stavudine; EFV: Efavirenz; FTC: Emtricitabine; HDL-C: High density lipoprotein cholesterol; HIV: Human immunodeficiency virus; LDL-c: Low density lipoprotein cholesterol; NVP: Nevirapine; TC: Total cholesterol; TDF: Tenofovir; TG: Triglycerides.

\section{Competing interests}

The authors declare that they have no competing interests.

\section{Authors' contributions}

Study conception and design: EKK, DCH and DKA. Participant recruitment: EKK, DCH, CKN, SB and BHC. Manuscript draft: JNK. Data analysis, interpretation and critical review of the manuscript: JNK, DCH, CKN, MFW, SB, JRK, BHC, DKA and EKK. All authors read and approved the final manuscript.

\section{Acknowledgments}

We are grateful to investigators and staff at Center for Infectious Disease Research in Zambia (CIDRZ) for facilitating this study. We are very grateful to the participants and staff at Chawama Clinic and Kalingalinga laboratory for their cooperation.

This study was supported by the University of Alabama at Birmingham (UAB) Department of Epidemiology, the UAB Nutrition Obesity Research Center grant \# P30DK056336; grants from the US National Institutes of Health (R21Al076430), including the Fogarty International Clinical Research Scholars and Fellows Program (R24-TW007988); and the Fulbright Scholars Program, US Department of State.

\section{Author details}

'Department of Medicine, Division of Epidemiology, Vanderbilt University, Nashville, TN 37203, USA. 'Department of Medicine, Division of Diabetes, Endocrinology and Metabolism, Vanderbilt University, Nashville, TN 37203, USA. ${ }^{3}$ Department of Medicine, Division of Infectious Diseases, Vanderbilt University, Nashville, TN 37203, USA. ${ }^{4}$ Institute for Global Health, Vanderbilt University, Nashville, TN 37203, USA. ${ }^{5}$ Department of Nutrition Sciences, University of Alabama at Birmingham, Birmingham, AL 35294, USA. ${ }^{6} \mathrm{Ndola}$ Central Hospital and Copperbelt University School of Medicine, Ndola, Zambia. ${ }^{7}$ Department of Medicine, University of Maryland, Baltimore, MD 21201, USA. ${ }^{8}$ Centre for Infectious Disease Research in Zambia, Lusaka, Zambia. ${ }^{9}$ Department of Obstetrics and Gynecology, University of North Carolina at Chapel Hill, Chapel Hill, NC 27599, USA. ${ }^{10}$ Department of Epidemiology, University of Alabama at Birmingham, Birmingham, AL 35294, USA.

Received: 12 February 2013 Accepted: 3 April 2013

Published: 10 April 2013

\section{References}

1. Friis-Moller N, Sabin CA, Weber R, D'Arminio Monforte A, El-Sadr WM, Reiss P, Thiebaut R, Morfeldt L, De Wit S, Pradier C, et al: Combination antiretroviral therapy and the risk of myocardial infarction. $N$ Engl J Med 2003, 349:1993-2003.

2. Triant VA, Lee H, Hadigan C, Grinspoon SK: Increased acute myocardial infarction rates and cardiovascular risk factors among patients with human immunodeficiency virus disease. J Clin Endocrinol Metab 2007, 92:2506-2512.

3. Brown TT, Cole SR, Li X, Kingsley LA, Palella FJ, Riddler SA, Visscher BR, Margolick JB, Dobs AS: Antiretroviral therapy and the prevalence and incidence of diabetes mellitus in the multicenter AIDS cohort study Arch Intern Med 2005, 165:1179-1184.

4. Dube MP, Stein JH, Aberg JA, Fichtenbaum CJ, Gerber JG, Tashima KT, Henry WK, Currier JS, Sprecher D, Glesby MJ, et al: Guidelines for the evaluation and management of dyslipidemia in human immunodeficiency virus (HIV)infected adults receiving antiretroviral therapy: recommendations of the HIV Medical Association of the Infectious Disease Society of America and the Adult AIDS Clinical Trials Group. Clin Infect Dis 2003, 37:613-627.

5. Jones R, Sawleshwarkar S, Michailidis C, Jackson A, Mandalia S, Stebbing J, Bower M, Nelson M, Gazzard BG, Moyle GJ: Impact of antiretroviral choice on hypercholesterolaemia events: the role of the nucleoside reverse transcriptase inhibitor backbone. HIV Med 2005, 6:396-402.

6. van der Valk M, Kastelein JJ, Murphy RL, van Leth F, Katlama C, Horban A, Glesby M, Behrens G, Clotet B, Stellato RK, et al: Nevirapine-containing antiretroviral therapy in HIV-1 infected patients results in an antiatherogenic lipid profile. AIDS 2001, 15:2407-2414.

7. Fontas $E$, van Leth F, Sabin CA, Friis-Moller N, Rickenbach M, D'Arminio Monforte A, Kirk O, Dupon M, Morfeldt L, Mateu S, et al: Lipid profiles in HIV-infected patients receiving combination antiretroviral therapy: are different antiretroviral drugs associated with different lipid profiles? J Infect Dis 2004, 189:1056-1074.

8. Passalaris JD, Sepkowitz KA, Glesby MJ: Coronary artery disease and human immunodeficiency virus infection. Clin Infect Dis 2000, 31:787-797.

9. Iloeje UH, Yuan Y, L'Italien G, Mauskopf J, Holmberg SD, Moorman AC, Wood KC, Moore RD: Protease inhibitor exposure and increased risk of cardiovascular disease in HIV-infected patients. HIV Med 2005, 6:37-44.

10. National Cholesterol Education Program Expert Panel on Detection EaToHBCiA: Third report of the national cholesterol education program (NCEP) expert panel on detection, evaluation, and treatment of high blood cholesterol in adults (Adult Treatment Panel III) final report. Circulation 2002, 106:3143-3421.

11. Group DADS, Friis-Moller N, Reiss P, Sabin CA, Weber R, Monforte A, El-Sadr W, Thiebaut R, De Wit S, Kirk O, et al: Class of antiretroviral drugs and the risk of myocardial infarction. N Engl J Med 2007, 356:1723-1735.

12. Group DADS, Sabin CA, Worm SW, Weber R, Reiss P, El-Sadr W, Dabis F, De Wit S, Law M, D'Arminio Monforte A, et al: Use of nucleoside reverse transcriptase inhibitors and risk of myocardial infarction in HIV-infected patients enrolled in the D:A:D study: a multi-cohort collaboration. Lancet 2008, 371:1417-1426.

13. Buchacz K, Weidle PJ, Moore D, Were W, Mermin J, Downing R, Kigozi A, Borkowf CB, Ndazima V, Brooks JT: Changes in lipid profile over 24 months among adults on first-line highly active antiretroviral therapy in the home-based AIDS care program in rural Uganda. J Acquir Immune Defic Syndr 2008, 47:304-311.

14. Armstrong C, Liu E, Okuma J, Spiegelman D, Guerino C, Njelekela M, Grinspoon S, Fawzi W, Hawkins C: Dyslipidemia in an HIV-positive antiretroviral treatment-naive population in Dar es Salaam, Tanzania. J Acquir Immune Defic Syndr 2011, 57:141-145.

15. Gupta A, Nadkarni G, Yang WT, Chandrasekhar A, Gupte N, Bisson GP, Hosseinipour M, Gummadi N: Early mortality in adults initiating antiretroviral therapy (ART) in low- and middle-income countries (LMIC): a systematic review and meta-analysis. PLoS One 2011, 6:e28691.

16. Egger M, Boulle A, Schechter M, Miotti P: Antiretroviral therapy in resource-poor settings: scaling up inequalities? Int J Epidemio/ 2005, 34:509-512. England.

17. Ngu JN, Heimburger DC, Arnett DK, Nyirenda CK, Potter D, Zulu I, Bosire CN, Bagchi S, Ye J, Chi BH, Kabagambe EK: Fasting triglyceride concentrations are associated with early mortality following antiretroviral therapy in Zambia. N A J Med Sci 2010, 3:79-88.

18. Heimburger DC, Koethe JR, Nyirenda C, Bosire C, Chiasera JM, Blevins M, Munoz AJ, Shepherd BE, Potter D, Zulu I, et al: Serum phosphate predicts early mortality in adults starting antiretroviral therapy in Lusaka, Zambia: a prospective cohort study. PLoS One 2010, 5:e10687.

19. Chi BH, Mwango A, Giganti M, Mulenga LB, Tambatamba-Chapula B, Reid SE, Bolton-Moore C, Chintu N, Mulenga PL, Stringer EM, et al: Early clinical and programmatic outcomes with tenofovir-based antiretroviral therapy in Zambia. J Acquir Immune Defic Syndr 2010, 54:63-70.

20. American Diabetes A: Diagnosis and classification of diabetes mellitus. Diabetes Care 2008, 31(Suppl 1):S55-S60.

21. Cakir MSR, Tosun O, Saka O, Karayalcin U: Reproducubility of fasting and OGT-derived insulin resistance indices in normoglycemic women. Can J Diabetes 2006, 30:46-51. 
22. Lee S, Choi S, Kim HJ, Chung YS, Lee KW, Lee HC, Huh KB, Kim DJ: Cutoff values of surrogate measures of insulin resistance for metabolic syndrome in Korean non-diabetic adults. J Korean Med Sci 2006, 21:695-700.

23. Matthews DR, Hosker JP, Rudenski AS, Naylor BA, Treacher DF, Turner RC: Homeostasis model assessment: insulin resistance and beta-cell function from fasting plasma glucose and insulin concentrations in man. Diabetologia 1985, 28:412-419.

24. Grunfeld C: Dyslipidemia and its treatment in HIV infection. Top HIV Med 2010, 18:112-118.

25. Duprez DA, Kuller LH, Tracy R, Otvos J, Cooper DA, Hoy J, Neuhaus J, Paton NI, Friis-Moller N, Lampe F, et al: Lipoprotein particle subclasses, cardiovascular disease and HIV infection. Atherosclerosis 2009, 207:524-529.

26. van Leth F, Phanuphak P, Stroes E, Gazzard B, Cahn P, Raffi F, Wood R, Bloch M, Katlama C, Kastelein JJ, et al: Nevirapine and efavirenz elicit different changes in lipid profiles in antiretroviral-therapy-naive patients infected with HIV-1. PLoS Med 2004, 1:e19.

27. Manuthu EM, Joshi MD, Lule GN, Karari E: Prevalence of dyslipidemia and dysglycaemia in HIV infected patients. East Afr Med J 2008, 85:10-17.

28. Pujari SN, Dravid A, Naik E, Bhagat S, Tash K, Nadler JP, Sinnott JT: Lipodystrophy and dyslipidemia among patients taking first-line, World Health Organization-recommended highly active antiretroviral therapy regimens in Western India. J Acquir Immune Defic Syndr 2005, 39:199-202.

29. Pefura Yone EW, Betyoumin AF, Kengne AP, Kaze Folefack FJ, Ngogang J: First-line antiretroviral therapy and dyslipidemia in people living with HIV-1 in Cameroon: a cross-sectional study. AIDS Res Ther 2011, 8:33.

30. Bonora E, Targher G, Alberiche M, Bonadonna RC, Saggiani F, Zenere MB Monauni T, Muggeo M: Homeostasis model assessment closely mirrors the glucose clamp technique in the assessment of insulin sensitivity: studies in subjects with various degrees of glucose tolerance and insulin sensitivity. Diabetes Care 2000, 23:57-63.

31. van Vonderen MG, Blumer RM, Hassink EA, Sutinen J, Ackermans MT, van Agtmael MA, Yki-Jarvinen H, Danner SA, Serlie MJ, Sauerwein HP, Reiss P: Insulin sensitivity in multiple pathways is differently affected during zidovudine/lamivudine-containing compared with NRTI-sparing combination antiretroviral therapy. J Acquir Immune Defic Syndr 2010 53:186-193.

32. Fleischman A, Johnsen S, Systrom DM, Hrovat M, Farrar CT, Frontera W, Fitch K, Thomas BJ, Torriani M, Cote HC, Grinspoon SK: Effects of a nucleoside reverse transcriptase inhibitor, stavudine, on glucose disposal and mitochondrial function in muscle of healthy adults. Am J Physiol Endocrinol Metab 2007, 292:E1666-E1673.

33. Groop LC: Insulin resistance: the fundamental trigger of type 2 diabetes. Diabetes Obes Metab 1999, 1(Suppl 1):S1-S7.

34. Cavaghan MK, Ehrmann DA, Polonsky KS: Interactions between insulin resistance and insulin secretion in the development of glucose intolerance. J Clin Invest 2000, 106:329-333.

35. Poirier P, Giles TD, Bray GA, Hong Y, Stern JS, Pi-Sunyer FX, Eckel RH, American Heart A, Obesity Committee of the Council on Nutrition PAaM: Obesity and cardiovascular disease: pathophysiology, evaluation, and effect of weight loss: an update of the 1997 American heart association scientific statement on obesity and heart disease from the Obesity Committee of the Council on nutrition, physical activity, and metabolism. Circulation 2006, 113:898-918.

36. Liu M, Chan CP, Yan BP, Zhang Q, Lam YY, Li RJ, Sanderson JE, Coats AJ, Sun JP, Yip GW, Yu CM: Albumin levels predict survival in patients with heart failure and preserved ejection fraction. Eur J Heart Fail 2012, 14:39-44.

37. Kabagambe EK, Judd SE, Howard VJ, Zakai NA, Jenny NS, Hsieh M, Warnock DG, Cushman M: Inflammation biomarkers and risk of all-cause mortality in the reasons for geographic and racial differences in stroke cohort. Am J Epidemiol 2011, 174:284-292.

38. Danesh J, Wheeler JG, Hirschfield GM, Eda S, Eiriksdottir G, Rumley A, Lowe $\mathrm{GD}$, Pepys MB, Gudnason V: C-reactive protein and other circulating markers of inflammation in the prediction of coronary heart disease. N Engl J Med 2004, 350:1387-1397.
39. Ridker PM, Hennekens $\mathrm{CH}$, Buring JE, Rifai N: C-reactive protein and other markers of inflammation in the prediction of cardiovascular disease in women. N Engl J Med 2000, 342:836-843.

40. Mak KH, Bhatt DL, Shao M, Haffner SM, Hamm CW, Hankey GJ, Johnston SC, Montalescot G, Steg PG, Steinhubl SR, et al: The influence of body mass index on mortality and bleeding among patients with or at high-risk of atherothrombotic disease. Eur Heart J 2009, 30:857-865.

doi:10.1186/1476-511X-12-50

Cite this article as: Kiage et al:: Cardiometabolic risk factors among HIV patients on antiretroviral therapy. Lipids in Health and Disease 2013 12:50.

\section{Submit your next manuscript to BioMed Central and take full advantage of:}

- Convenient online submission

- Thorough peer review

- No space constraints or color figure charges

- Immediate publication on acceptance

- Inclusion in PubMed, CAS, Scopus and Google Scholar

- Research which is freely available for redistribution 